\title{
Non-Adherence to Antiretroviral Treatment by People Living with HIVIAIDS in Black Communities in South Africa: Socio-Cultural Challenges
}

\author{
J.G. Kheswa \\ Department of Psychology, University of Fort Hare, \\ Private Bag X 1314, Alice, 5700, South Africa \\ Email: jkheswa@ufh.ac.za
}

\section{Doi:10.5901/mjss.2014.v5n14p450}

\begin{abstract}
A disproportionately high number of poor black population living in both rural and urban areas in South Africa, experience barriers to accessing ARVs, despite the efforts made by the government. Various scholars cite that cultural beliefs, poverty, witchcraft, lack of family support, gender-based violence and substance abuse derail the progress of HIV treatment programmes. This paper, therefore discusses the challenges faced by PLWHA with the aim to provide an integrated approach to strengthen the support base required for adherence to ARV treatment. The findings show that due to discrimination PLWHA experience the side-effects, depression and other opportunistic infections such Kaposi's sarcoma, even death, leaving children as orphans.
\end{abstract}

Keywords: HIVIAIDS, ARVs, non-adherence, PLWHA, patients, discrimination, South Africa

\section{Introduction}

According to Regensburg (2013) there has an initiative in South Africa of a fixed dose combination of two or more active drug in a single pill. Instead of people living with HIVIAIDS (PLWHA) taking two or three different pills, they can take one pill a day which includes several ARVs. The fixed combination contain tenafivir, TDF, FTC, or 3TC and efavirenz first line regimen, and Atripla-tribuss which has been made available in private sectors and developed public sectors starting from 2013 (Dunn, 2013). Theatripla-tribuss fixed dose combination is pharmaceutically proven to contribute to PLWHA's adherence to ARV treatment as they are effective (Marteen, 2013). According to Treatment Action Campaign (2007), antiretroviral drugs are usually referred to as ARVs; they are the only approved medicines that can stop the HIV germs from multiplying in one's body. They keep the virus weak and keep the viral load or the level of the virus in one's blood very low, in that way the immune system gets protected and help patients living with HIV to have longer and healthier lives. Mhlongo (2010), advocates like many researchers that antiretroviral drugs are the effective treatment that is recommended for PLWHA, who had undergone testing and counselling from the clinics or qualified medical practitioners, and whose CD4 count is below 200 and have had severe opportunistic infections (e.g. Tuberculosis, Diarrhoea). It could be said that low or non-adherence seriously compromises the value of this treatment

Owing to multiple factors which are a barrier to adherence to HIVIAIDS treatment, Kagee, Le Roux and Dick (2007), found that poverty affects the adherence to care, for example, patients with no financial power struggle to travel to the clinics that provide ARV treatment. To confirm this, in a quantitative study conducted at Chris Hani Baragwanath Academic Hospital (CHBAH) in Soweto, Gauteng Province, South Africa, Jonsson, Furin, Jeenah, Moosa, Sivepersad, Kalatatis and Schoeman (2014), found that among patients who were no longer accessing ARVs, 25\% had moved to other catchment areas (e.g. Orange-Farms, informal settlements). Furthermore, combined stresses associated with poverty such as inadequate housing, unemployment and forced relocation tend to aggravate the health condition of people who had already started their treatment. Effects of poverty such as shelter, hunger, violence from others, and lack of social support contribute immensely to non-adherence to ARV treatment, and in South Africa there was high level of poverty and unemployment in 2010, pitching $67 \%$ of people over the age of 18 and the majority being blacks (Holborn \& Eddy, 2011 As a result, patients ran out of ARV treatment due to the lack of money for food and transport (Maokisa, 2011; Reniers \& Armbruster, 2012).

Mills, Nachega, Bangsberg, Sigh and Rachlis (2006) argue that when PLWHA take their ARVs without food, there may be severe complications such as ulcers, haemorrhage (internal bleeding) and meningitis. Therefore, to prevent opportunistic infections such as tuberculosis (TB) and pneumonia, Treatment Action Campaign (2007), calls for nutritional 
support in the form of food- parcels and safe water for PLWHA from the private sectors, to remain in the workplace. Kagee (2007) argues that in many black communities, there is lack of social support for PLWHA, especially towards women. Sayles, Wong, Kinsler, Martins and Cunningham (2006), noted that women who are HIV positive abandon ARV treatment find themselves in a difficult position to take treatment for fear of reprisal and rejection. They often prefer to remain silent, and continue neither to negotiate safe-sex nor to propose to their husbands to go for HIV-tests (Mabunda, 2004). In a quantitative study conducted among black South African women, Murray, Semrou, Semrau, Mc Curley, Thea, Mwiya, Kankasa and Bass (2009), found that 39.9\% indicated that their fears were based on the fact that their husbands or partners might leave them and be accused of having infected them. According to Reniers and Armbruster (2012), the danger of disclosure of HIV positive status may be linked to the experience of negative life events which involve violence, rejection, stigmatisation and divorce or separation. No wonder why PLWHA who are on ARVs are likely hide their treatment from their partners.

Against this background, this research paper intends to explore the causal factors of non-adherence from sociocultural perspective with the aim to provide a multi-dimensional approach to eradicate stigmatization that prevails in South Africa among blacks.

\subsection{Culture and Belief Systems}

Point of departure in understanding how people make sense of their illness, the patient's cultural beliefs and practices must be explored. Bogart, Kalichman and Simbayi (2008), found that many South Africans who are reluctant to know their health-status, hold on to the myth that HIVIAIDS was developed by White people to control their black counterparts, and that also contributes to non-adherence. Since, in South Africa, 60 to $80 \%$ of people especially in rural areas (e.g. Limpopo, KwaZulu- Natal and Eastern Cape) rely on traditional healing for mental and physical treatment (Wreford, 2005), Nattrass (2005), found that an alarming proportion of HIV- positive people have the tendency to stop taking their ARVs once they had sought help from traditional healers. Once they have been to "isangoma"(diviner), or prophecy "ukuhlahluba", in most cases, the revelation tend to indicate that their ancestors might be angry by not slaughtering cows or goats, hence they experience misfortune, as if upon splitting of blood "tshollo yamadi" would facilitate cure.

\subsection{Religious Belief}

According to Zou, Yamanaka, John, Ostermann and Thielman (2009), religiously, HIV stigma is shame related, as it is believed that HIV is a punishment from God or people living with HIVIAIDS have not followed the word of God. PLWHA who disclose to their pastors, a prayer is conducted to cure HIV and because of the patient's faith and fear of doubting God's abilities, they stop the ARV treatment. In both developed and developing countries, patients tend to respect their religious beliefs alike. For example, Wasti, Simkhada, Randall, Freeman and van Teijlingen (2012), found that among Muslims in Nepal, HIV-patients do not stick to their routine, but skip their medication due to the festivals such as Ramadan, which requires them to fast from sunrise till sunset.

\subsection{Witchcraft}

The belief in witchcraft in many black communities is associated with HIVIAIDS infection. The belief of evil spirits and witchcraft can lead to non-adherence to the treatment as PLWHA believe that if they perform rituals they will be cleansed, and healed of the HIV. According to Ashforth and Nattrass (2006), some of PLWHA understood HIV infection as a form of pollution and often use the term 'dirty blood', so they will use laxatives and induce vomiting to cleanse the 'dirt' out of their blood. The "sangomas" may attribute the source of sickness to jealousy, pure malice, anger and revenge from friends, neighbours and relatives. As a result, Nattrass (2005), found that PLWHA would stop taking their ARVs and use powders, herbal liquids and lotions as prescription to cure HIVIAIDS. In the process, they would drink substance that leave them dehydrated as a result of purging (vomit) since the belief is that they have been bewitched. To date, no traditional medicines have been scientifically proven to cure HIVIAIDS.

\subsection{Gender Violence and Male dominance}

According to Murray et al. (2009), non - adherence is inextricably linked to fear of being physically and emotionally abused. Kagee et al (2011), in a scientific study conducted in Cape Town, found that women are at a greater risk of being victimized when it comes to HIVIAIDS and treatment. They prefer to remain silent, engage in unsafe sex and drink their 
ARVs occasionally, when their sexual partners are not around (Reimien \& Mellins, 2007). Drawing from gender role strain theory by Agnew (1985), which is based on the concept that male sexual behaviours are influenced by cultural norms, women may even be afraid of negotiating safe sex. Males may believe that risk taking is an expression of masculinity and therefore tend to have casual sexual relationships and do not practice safe sex, indulge in alcohol use and violate the right of their partners (Jewkes, Levin \& Penn-Kekana, 2003).

\subsection{Stigma, Prejudice and Discrimination}

Globally, stigma and discrimination are major obstacles leading to treatment seeking behaviour and effective HIVIAIDS prevention and care, especially in Sub-Saharan Africa. Stigma is rooted in deviance from the values and social norms of a communityand known as a risk factor of lower levels of adherence to treatment especially, ARVs (Kagee, 2007). Because of stigma and discrimination, PLWHA tend to often miss their doses as a result of fear of being identified as HIV positive, or as seen at the clinics and being on ARV medication for the rest of their lives (Monjok, Smesny, Okokon, Mgbere \& Essien, 2010). For example, in Western Cape Province, HIV is referred to as "ulwazi" which means "that thing", PLWHA do not want to be associated with ARVs and default (Cloete, Strebel, Simbayi, Van Wyk, Henda \& Nqeketho, 2010). However, when one's self-efficacy- an ability to take treatment with good intentions, intrinsic motivation and coping skills are intact, PLWHA may approach life with meaning and purpose as suggested by Victor Frankl's logotherapy (Schultz \& Schultz, 2013).

\subsection{Discrimination in churches}

Discrimination against PLWHA in churches is rife and PLWHA are regarded as sinful and lacking in morality, especially if they are homosexuals. This affects individuals who are HIV positive adversely in relation to treatment and adherence. For example, an individual may not feel comfortable taking treatment in front of his or her congregants because of fear of being ostracized and rejected (Geinrich \& Brathwaite, 2005). According to Doupe (2003), Hindu organisations believed that HIVIAIDS occurred among homosexuals and that individuals living with HIVIAIDS may feel discriminated and hated. HIVIAIDS in Hindu is considered as an unhygienic situation; individuals with HIVIAIDS are unclean and would be expected to stay away from organised worship. In a study conducted by Doupe (2003) of World Council of Churches, it was discovered that in different countries pastors refused to anoint HIV infected people, some forced PLWHA to publicly confess the "sins" that caused them to be infected. This proved that PLWHA are discriminated in their churches worldwide by people who were supposed to support them.

\subsection{Lack of family support}

According to Murray et al. (2009), family support is vital to the patient in a sense that if the family provide warmth, unconditional regard and non-judgemental attitude the patient may find it easy to cope with whatever challenges he/ she might come across. Family support boosts the patients' self-esteem and it becomes easy for the patient to adhere to treatment and believing that he/ she will have a long and healthy life. In contrast, if a patient does not have the support it becomes difficult for him/her because what will follow is ill-treatment from family and the person will lose hope and that will lead the person to default on treatment (Goldsmith \& Albrecht, 2011). For example, in a qualitative research study carried out in Alice, Eastern Cape, South Africa, by social workers among Xhosa speaking out-patients who take ARV treatment, Sam, Kona, Mboto, Mtiki and Mbanga (2013), found that discrimination at family level, workplace and community at large, could have devastating effect on the mental well-being of PLHWA and contribute to non- adherence. A female (Aged 45) was quoted as saying:

"Ndacalulwa yifamily yam emva kokuba ndiyixelele ngokuba ndichaphazelekile yintsholongwane kagawulayo, babengafuni nokuba ndipheke, kukhe kuthiwe ndazifunela ngokwam ukuba HIV- positive".

The participant was discriminated by her family after she revealed that she was HIV positive. Her family did not even want her to cook as she might infect them, moreover, she was sexually promiscuous.

However, Taddeo, Egedy and Frappier (2008) argue that when PLHWA have close and supportive relationships with family and friends, internal locus of control and efficacy of treatment, they, in turn, withstand challenges and rebuild their lives better than those who are not dependent on others. Based on the research findings of the study conducted in KwaZulu-Natal by Dageid, Sliep, Akintola and Duckert (2011), PLWHA with higher socio-economic status are more 
resilient and emotionally supported as compared to their counterparts from lower socio-economic status.

\subsection{Substance Abuse}

According to Kagee (2007), alcohol abuse contributes to non-adherence to ARV treatment by PLWHA. Drawing from alcohol myopia theory which states that large amounts of alcohol consumption lead to the impairment of the brain until the drinker loses consciousness, PLWHA may default and in that process the viral load increases, the Cd4 count drops and the treatment eventually resisting the system (Braithwaite \& Bryant, 2010). Alcohol use and subsequent malnutrition may triggerdelirium- a common complication of underlying organic brain disease. It is often present among PLWHA with low CD4 count and those on ARV treatment. PLWHA with delirium cannot adhere properly to the ARV treatment due to their cognitive functioning that is unstable (South African Medical Research Council, 2011). It is therefore recommended that PLWHA may receive as much emotional support as possible to avoid non adherence.

Once under the influence of alcohol, PLWHA may have tendencies to deny their health status and continue to practice unsafe sex (WHO, 2006). According to Molina, Happel, Zang, Kolls and Nelson (2010), alcohol abuse impacts negatively on the gastrointestinal and respiratory tract immune system, thereby resisting the ARVs from effective functioning against opportunistic infections. For example, in a quantitative study conducted in the Cape Metropolitan area, South Africa, of all the participants who had TB status, 14\% reported harmful use of alcohol and other drugs compared to $11 \%$ that did not have alcohol and drug problems (Kader, Seedat, Govender, Koch, \& Parry, 2013). Of great concern are the PLWHA travelling further to shebeens where they are not known and start patronizing (meeting new sexual partners) and practice unsafe sex (Chang, 2008; Jewkes et al., 2011). It is disappointing to learn that 400 million condoms are distributed annually by the Department of Health and there are still people who do not practice safe sex, yet knowing their health-status.

\subsection{Denial}

According to Swartz et al., (2011) denial is defence mechanism, an outright refusal to admit or recognize that something has occurred or is currently occurring. According to Xochihua-Diaz (2009), denial and fear of HIV infection amongst newly diagnosed patients, plays a major role towards refusal to start with the ARV treatment. Patients in denial and who are mis-informed about HIV and treatment have the tendency not to adhere to treatment and practice unsafe sex. Mashego (2004) and France-Presse (2004), found that in most African societies there is much ignorance and misinformation about proper condom use and related topics especially amongst PLWHA.Condoms must be promoted and branded as a preventive measure against disease, not only against pregnancy, in Africa where this pandemic continues to spread and as a way of escaping negative health consequences.

\subsection{Depression}

HIVIAIDS patients who experience anxiety and forgetfulness tend to overlook their psychological wellbeing and eventually become depressed (Kilbourne, Reynolds, Good, \& Sereika, 2005; Wagner, Googins, Remien, Rosen, Simoni, Bangsberg \& Liu, 2011). They may be overwhelmed by helplessness and hopelessness, become withdrawn, be emotionally detached and be preoccupied with suicidal ideation (Kagee, 2007). Thom (2009), states that depression has potential of being a challenge to successful treatment programs, as PLWHA often have negative thoughts because of the side effects the treatment has. A patient may be unmotivated or reluctant to honour or attend clinic appointments, especially when struck by poverty and lack social support. Rochat, Richter, Doll, Buthelezi, Tomkins and Stein (2006), confirm that HIV triggers central nervous system and affects memory. In Limpopo Province, South Africa, Thom (2009) found that patients who were inconsistent with regard to taking their ARVs, they displayed depressive symptoms. Almost $21 \%$ reported anxiety disorders and drug- dependence. Similarly, in Cape- Town, South Africa, Brandt (2009), reported that majority of PLWHA, had displayed the most common clinical symptoms- emotional withdrawal, sadness and reduced sleep.

\subsection{Migration}

Kagee et al. (2011) state types of migration that is voluntary migration and forced migration. Furthermore, internal migration happen for economic reason and is common to provinces who experienced low income, as people often seek employment in areas away from their homes. Reimien and Mellins (2007), migration can be caused by divorce and force 
HIV- positive women to engage in transactional sex for survival. In such cases, women may meet new sexual partners and be prone to victimization especially when they are unemployed. Aligned with social exchange theory, re- infection is likely to occur because in a sexual relationship marked by money in exchange of sex; males would prefer flesh to flesh and never discuss their health status (Mah \& Halperin, 2010; Yutyunghong \& Scott, 2009). Based on what is cited above, it is clear that the challenge faced by HIV- counsellors is to educate PLWHA that when migrating to work or study far from home they must visit to the nearest clinic to ensure continuity of adherence to ARV treatment.

\section{Consequences of Non- Adherence to ARV treatment}

Various scholars assert that when PLWHA lack social support, they may suffer unbearable consequences (frustration, anger and hopelessness). Due to high viral load, they may suffer opportunistic infections (e.g. pulmonary tuberculosis, crypotocal meningitis) as well as diminished quality of life and death- leaving children as orphans (KZN Department of Health, 2004; Luszczynska, Sarkar \& Knoll, 2006).

\subsection{Resistance to ARV treatment}

Remien and Mellins (2007) elucidate that missed doses of ART are associated with the development of resistant virus that may lead to treatment failure, viral progression, and the possible transmission of ART-resistant strains of HIV. The National Minority AIDS Council (2012) reveals that although the treatment resistance may develop, there are HIV treatment options to manage drug resistant HIV. Ashforth and Nattrass (2006) argue that there is also question of protection and long-term adherence and transmission of ART resistance strain to partners. For an example, if a PLWHA is resistant to the ARV treatment her or his partner will also be resistant to ARV treatment.

\subsection{Side-effects of ARVs}

Nachega, Lehman, Hlatshwayo, Mothopeng, Chaisson and Karstaedt (2005) mentioned that sides effects cite by patients who use ARV treatment are body rash, swollen legs, nausea, headache, increase heart rate, diarrhoea and vomiting. Antiretroviral side effects have negative impact on patients and their quality of life and adherence to treatment. They further argue that the side effects also have contribute immensely to adherence because, some PLWHA when they experience this sides effects they tend to stop taking the treatment that leads to severe illness and death.

\subsection{Kaposi Sacorma}

Luszczynska et al., (2006) define Kaposi's sarcoma as a malignant tumor found under the skin and in the lining of the mouth and rectum, characterized by brown or purplish spots. It is rare in persons who are not HIV infected and may thought of as an opportunistic infection in persons with damaged immune systems and low CD4 count. Kaposi's sarcoma is a cancer of blood vessels mainly affecting the skin, mouth and lymph glands and emanates from "Human Harpes virus 8" (HHV8).When the HHV8 develops into Kaposi sarcoma the most obvious signs are lesions found in the skin usually on the legs and feet and in the mouth.

\subsection{Peripheral Neuropathy}

Peripheral neuropathy is classic balanced stocking glove, which begins in the feet and travels proximally over time. It is also mentioned that Peripheral neuropathy in PLWHA is caused by stavudine and didanosine. Peripheral neuropathy can cause balance problems and abnormal painful sensation (numbness). This can also make the PLWHA to have fears of continuing with the ARV treatment (Mills et al., 2006).

\subsection{Orphanhood}

According to Battacharya, Rajeshwari and Saxena (2010), about 15 million children have been orphaned and a further 19 million will be orphaned in 2015 because of parental death due to non-adherence. Orphans living with relatives and may be less likely to receive basic healthcare and primary education. Children orphaned by HIV are devastated in many ways (Sutcliffe, van Dyk, Bolton, Persaud \& Moss, 2008). For example,

- They may become child headed households with the elder child responsible for their siblings 
- Some orphans may end up being street children while others staying with extended families.

- They may drop out of school prematurely and likely to engage in criminal activities for survival., since they lack parental guidance and supervision.

- They may be most likely to contract STIs, including HIVIAIDS as they may practice unsafe sex with multiple partners in exchange for money, at an early age.

\section{Recommendations}

The following are the recommendations made on the lessons learnt from different phases of the study.

- The adoption of continuum care with a holistic approach to offer comprehensive services to HIV- patients, from the diagnosis to treatment, as suggested by Department of Health (2004). Please refer to the figure below.

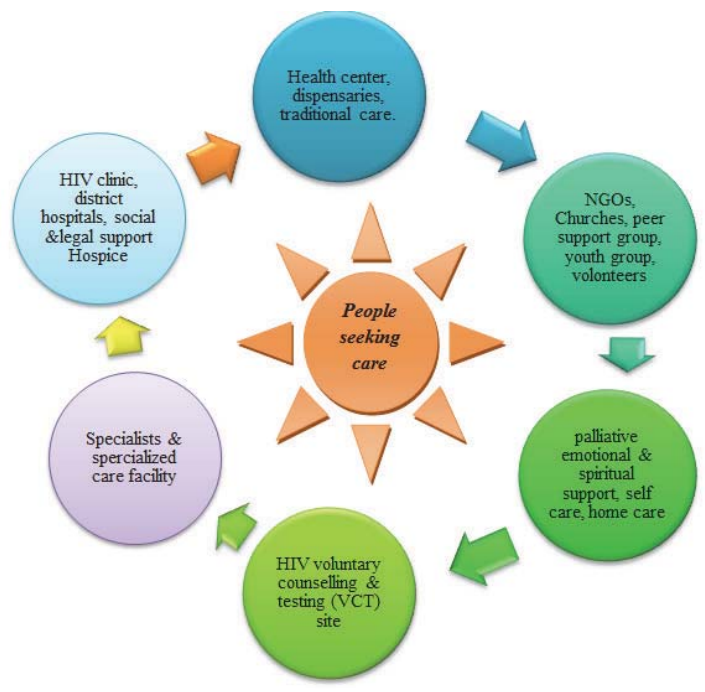

Figure 1: Continuum of Care Approach (Adapted from Department of Health, 2004).

- Multi-disciplinary team approach should be strengthened in providing social and spiritual support to PLWHA in order to overcome discrimination and associated stigma. In other words, peer-support groups, churches, NonGovernmental Groups (NGOs) and churches, should take a leading role in establishing programmes to ensure that PLWHA adhere to their ARV -treatment.

- Primary health workers should adopt Batho-Pele principle approach by being professional (i.e. nonjudgemental attitude towards the patients, confidentiality, accountability and respect for human dignity).

Finally, for pregnant mothers, psycho-educational programmes such as family planning and prevention of motherto child- transmission (PMTCT) be introduced. Home-based care, mobile clinics for people living in villages should be implemented to reduce mortality rate due to non-adherence

\section{References}

Ashforth, A., \& Nattrass, N. (2006). Ambiguities of 'culture' and the Antiretroviral rollout in South Africa. Centre for Social Sciences Research: AIDS and Society Research Unit, CSSR Working Paper no. 156.

Battacharya, D, Rajeshwari, A \& Saxena, R., (2010). Demographic and clinical features of orphans at a paediatric HIV centre in India. Indian Journal of paediatrics. Vol 77: 627-628.

Bhat, V. G., Ramburuth, M., Singh, M., Titi, O. , Antony, A. P. Chiya, L., Irusen, E. M., Mtyapi, P. P., Mofoka, M. E., Zibeke, A., ChereSao, L. A. , Gwadiso, N. Sethathi, N. C. , Mbondwana, S. R., \&Msengana, M. (2010). Factors associated with poor adherence to anti-retroviral therapy in patients attending a rural health centre in South Africa. Eur J Clin Microbiol Infect Dis 29: 947-953. DOI 10.1007/s10096-010-0949- 4

Brandt, R. (2009). The mental health of people living with HIVIAIDS in Africa: a systematic review. African Journal of AIDS Research, 


\section{$8(2), 123-133$}

Chang, J. (2008). The role of anonymity in deindividuation behaviour: A comparison of deindividuation theory and the social identity model of deindividuation effects (SIDE). Undergraduate journal of Baylor University, 6 (1), 1-8.

Cloete, A, Strebel, A, Simbayi, L, Henda, N \&Nqeketho, A. (2010). Challenges faced by people living with HIVIAIDS IN Cape Town, South Africa. Issues for Group Reduction interventions. Vol 10:4

Coon, D., \& Mitterer. (2007). Introduction to Psychology. Gateways to Mind and Behaviour. Wadsworth Cengage Learning: Australia.

Dageid, W., Sliep, Y., Akintola, O., and Duckert, F. (2011).Response-ability in the Era of AIDS.African Sun Media.

Department of Health Monitoring Review Progress Report on the Implementation of the Comprehensive HIV and AIDS Care, Management and Treatment Programme. Issue 1. Sept 2004. http:// www.doh.gov.za

Doupe, A. (2003). World Council of Churches: Partnership between Churches and People Living with HIV/AIDS. $8^{\text {th }}$ General Assembly, Yaunde, Cameroon

Dunn L. (2013). Health Care professionals news letter Aids for Aids, fixed dosed combination. August-issue 35, Cape Town

France-Presse, A. (2004). South African health ministry sees Aids pandemic stabilizing. 23rd September 2004.

Geinrich, G.L., \& Brathwaite, B, A. (2005). Response of Religious Groups to HIVIAIDS as a sexually transmitted infection in Trinidad, BMC Health.

Goldsmith, D.J, \& Albrecht, T. L. (2011). Social Support, social networks and health. Handbook of health communication. (2nded.). Routledge: New York.

Goudge, J., Ngoma, B., Manderson, L., \& Schneider, H. (2009). Stigma, identity and resistance among people living with HIV in South Africa: original article. SAHARA: Journal of Social Aspects of HIVIAIDS Research Alliance, 6(3), 94-104.

Holzemer, W.L., Uys, L., Makoae, L., Stewart, A., Phethu, R., Dlamini, P.S., Greef, M., Kohi, T.W., Chirwa, M., Cuca, Y. \& Naidoo J. 2007.A conceptual model of HIVIAIDS stigma from five African Countries.Journal of Advanced Nursing, 58(6), 541-551

Kagee, A. (2007) Adherence to antiretroviral therapy in the context of the national roll-out in South Africa: Defining a research agenda for psychology. South African Journal of Psychology.38 (2). 413- 419

Kilbourne, A.M., Reynolds, C. F., Good, C. B., \& Sereika, S. M. (2005). How does depression influence diabetes medication adherence in older patients? American Journal of Geriatric Psychiatry, 13, 202-210.

Jewkes, R., \& Morrell, R. (2012). Sexuality and the limits of agency among South African teenage women: Theorising femininities and their connections to HIV risk practises. Social Science \& Medicine, 74(11), 1729-1737.

Jewkes, R., Morrell, R., Sikweyiya, Y., Dunkle, K., \& Penn-Kekana, L. (2012). Transactional relationships and sex with a woman in prostitution: prevalence and patterns in a representative sample of South African men. BMC public health, 12(1), 325.

Johnson, G., Furin, J., Jeenah, F., Moosa, M. Y., Sivepersad, R., Kalafatis, F., \& Schoeman, J. (2013). Human rights, mental illness and HIV: The Luthando Neuropsychiatric HIV Clinic in Soweto, South Africa. Health and Human Rights: An International Journal. http://www.hhrjournal.org/2013/08/20/human-rights-mental-illness-and-hiv-the-lutha..

Kader, R., Seedat, S., Govender, R., Koch, J. R., \& Parry, C. D. (2013). Hazardous and Harmful use of Alcohol and/or Other Drugs and Health Status Among South African Patients Attending HIV Clinics. AIDS and Behavior, 1-10.

KZN Department of Health (2004). Adherence in HIV Care and Treatment: Training-ARV Treatment \& Care for HIV infected.

Luszczynska, A., Sarkar, Y., \& Knoll, N. (2006). Received Social support, Self efficacy and finding benefits in disease as predators of physical functioning and adherence to antiretroviral therapy. Patient Education and Counselling. Vol 66:38-42

Maartens, G. (2013). Health Care professionals.Newsletter for Aids, fixed dosed combination. August-issue 35, Cape Town.

Mabunda, G. (2004). HIV Knowledge and Practices among Rural South Africans. Journal of Nursing Scholarship, (36)4,300-304

Mah, T.L., \& Halperin, D.T. (2010). Concurrent sexual partnerships and the HIV epidemics in Africa: evidenceto move forward. AIDS and Behaviour, 14 (1),11-17

Mashego, B.E. (2004). Perceptions and attitudes on condom use among male and female students of the University of Zululand. Empangeni: KwaDlangezwa.

Maokisa, T. C. (2011). Factors Contributing to Poor Antiretroviral Therapy Adherence among patients at Jwaneng Mine Hospital: Masa Clinic in Botswana.

Mhlongo, E. M. (2010). An exploration of the experiences of clients on antiretroviral therapy and their health care providers in KwaZulu Natal. (Doctoral dissertation, Faculty of Health Sciences, University of the Witwatersrand): Johannesburg.

Mills, E.J., Nachega, J.B., Bangsberg. D.R., Sigh. S., Rachlis, B. (2006). Adherence to HAART: Systematic review of developed and developing notion patient-reported barriers and reported barrier and facilitators. Plos Med, Vol.3: 438-440.

Molina PE, Happel KI, Zang P, Kolls JK, Nelson S. . (2010). Focus on alcohol and the immune system. Alcohol Res Health, 33(1): 97108.

Morfaw, F., Mbuagbaw, L., Thabane, L., Rodrigues, C., Wunderlich, A. P, Nana, P., and Kunda, J. (2013). Male involvement in prevention programs of mother to child transmission of HIV: a systemic review to identify barriers and facilitators. Biomed Central Vol. (2), pp. 5

Monjok, E., Smesny, A., Okokon, I. B, Mgbere\&Essien, E,J. (2010). Adherence to antiretroviral therapy in Nigeria: an overview of research studies and implications for policy and practise, Dove Press Journal.

Murray, L.K., Semrou, K., Semrau, K., Mc Curley, E., Thea, M.D., Scott, N., Mwiya, M., Kankasa,C., Bass,J. (2009). Barriers to acceptance and adherence of Antiretroviral therapy in urban Zambian women: A qualitative study, Vol 21: $78-86$

Nachega, J. B., Lehman, D. A., Hlatshwayo, D., Mothopeng, R., Chaisson, R. E., \& Karstaedt, A. S. (2005). HIVIAIDS and antiretroviral treatment knowledge, attitudes, beliefs, and practices in HIV-infected adults in Soweto, South Africa. Journal of Acquired Immune 
Deficiency Syndromes, 38, 196-201.

Nattrass, N. (2005). Rolling out antiretroviral treatment in South Africa: Economic and ethical challenges. In A. A. van Niekerk\& L. M. Kopelman (eds.), Ethics \& AIDS in Africa: The challenge to our thinking (pp. 39-52). David Philip: Cape-Town.

Regensberg, L (2013). Health Care professionals news letter Aids for Aids, fixed dosed combination. August-issue 35, Cape Town.

Remien, R. H., \&Mellins, C. A. (2007). Long-term psychosocial challenges for people living with HIV: Let's not forget the individual in our global response to the pandemic. AIDS Care Vol. 21: 55-63

Reniers, G. \&Armbruster, B. (2012).HIV Status Awareness, Partnership Dissolution and HIV Transmition in Generalised Epidermics.PLOs ONE, Vol. 7 (12).

Rochat, T. J., Richter, L. M., Doll, H. A., Buthelezi, N. P., Tomkins, A., \& Stein, A. (2006). Depression among pregnant rural South African women undergoing HIV testing. JAMA: Journal of the American Medical Association, 295, 1376-1378.

Sayles, J.N., Wong, Kinsler, J.J., Martins, D and Cunningham,E., (2009). The association of stigma with self-reported access to medical care and antiretroviral therapy adherence in persons living with Aids. Journal of General Medicine. Vol 24(10): 1101-1108.

Sam, N., Kona, W., Mboto, Y., Mtiki, V., \& Mbanga,M. (2013). An exploratory study of adherence and challenges to antiretroviral treatment for PLWHA: A case of Victoria Hospital ARV-Site (Alice).[Bachelor of Social Work dissertation]. University of Fort Hare: Alice.

Schultz, D.P., \& Schultz, S.E. (2013). Theories of Personality. International Edition. (10 $0^{\text {th }}$ ed.). Wadsworth Cengage Learning: USA

South African Medical Research Council. (2011). PEPFAR Southern and Eastern Africa meeting on alcohol and HIV Prevention: PLWHA, Alcohol and ART Adherence. Namibia.

Sutcliffe, C.G., van Dijk, J.H., Bolton, C., Persaud, D., Moss, W.J. (2008). Effectiveness of antiretroviral therapy among HIV-infected children in sub-Saharan Africa. Lancet Infect Dis 8(8):477-489.

Swartz, L., de la Rey, C., Duncan, N., \& Townsend, L. (2011). Psychology: an introduction. (3rded.). Oxford University Press: Cape Town.

Taddeo, D., Egedy, M., and Frappier, J. Y. (2008). Adherence to treatment in adolescents. Paediatric Child Health. Vol. 13 (1): 19

Thom, R. Mental disorders in HIV-infected individuals attending various HIV treatment sites in South Africa. th $^{\text {th }}$ South African AIDS Conference, Durban, 2009.

Treatment Action Campaign. (2007). National executive Document for discussion end proposed congress Resolution Based on Organisation Review Commission and Evaluation, 24 September 2007.

Wagner, G. J., Googins, K., Remien, H.R., Rosen, M.I., Simoni, J., Bangsberg, D.R., \& Liu, H. (2011). A closer look at depression and its relationship to HIV Antiretroviral Adherence: National Institute of health. Vol 42(3): 352-360

Wasti, S.P., Randall, J., Simkhanda, P., \& Teijlingen, E.(2011). In what way do Nepalese cultural factors affect adherence to antiretroviral treatment in Nepal. Health Science Journal. Vol. (1) 37-40

WHO. (2006). WHO HIV prevention and treatment guidelines. Antiretroviral drugs for treating pregnant women and preventing HIV infection in infants, towards universal access: recommendations for a public health approach. Geneva, World Health Organization.

Xochihua-Diaz, L (2009). Adherence to antiretroviral treatment in adolescents. Bol Med Hosp Infant Mex, Vol 66, 9-14 